Rapid Reviews COVID-19•

\title{
Reviews of "SARS-CoV-2 Aerosol Transmission in Schools: The Effectiveness of Different Interventions"
}

Jacob Bueno de Mesquita, Ph.D. ${ }^{1}$, Richard M. Lynch, Ph.D. ${ }^{2}$, Brian Pavilonis ${ }^{3}$

${ }^{1}$ Berkeley Laboratory: E 0 Lawrence Berkeley National Laboratory, UNITED STATES, ${ }^{2}$ Preferred Management Corporation, President, UNITED STATES, ${ }^{3}$ CUNY School of Public Health

Published on: Sep 19, 2021

License: Creative Commons Attribution 4.0 International License (CC-BY 4.0). 
To read the original manuscript, click the link above.

Summary of Reviews: Reviewers find this a straightforward modelling study, though ask for clarification on some assumptions and emphasize that the results may apply only to naturally-ventilated classrooms.

Reviewer 1 (Jacob Bueno de Mesquita, Ph.D) |

Reviewer 2 (Richard M. Lynch, Ph.D) | प्र० $\square$

Reviewer 3: (Brian Pavilonis)

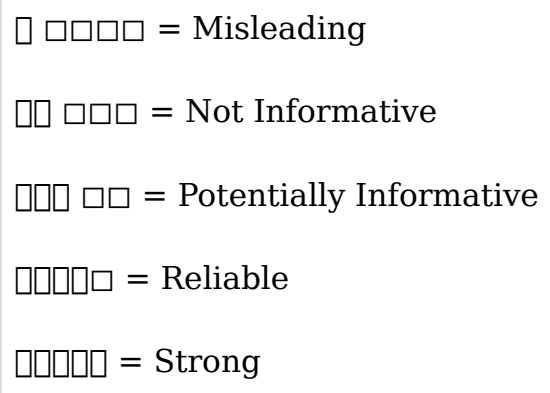

To read the reviews, click the links below. 